\title{
Algunos aspectos centrales de la filosofia de Ignacio Ellacuría
}

\author{
Marcelo Correa Schnake \\ Universidad Católica del Maule, Talca
}

RESUMEN: En el presente trabajo se plantea que el sello distintivo de la filosofía de Ignacio Ellacuría es la centralidad de la noción de "realidad histórica", planteada a partir de las ideas zubirianas acerca de la realidad y la inteligencia humana.

ABSTRACT: The distinctive character of the philosophy of Ignacio Ellacuria is the centrality of the concept known as "bistoric reality", which is related with the concepts of reality and buman intelligence in Zubini.

El año 2005 se conmemoran dieciséis años de la muerte de Ignacio Ellacuría, filósofo y teólogo de la liberación. Este pensador se destacó, entre otras cosas, por recoger las críticas tanto de intelectuales como de la propia Iglesia a dicha teología. Para atender a estos cuestionamientos, tomó una serie de iniciativas, una de las cuales consistió en hacerse cargo de los presupuestos filosóficos de la Teología de la Liberación en respuesta a la crítica por la utilización de categorías marxistas en el análisis de la historia', con el consiguiente riesgo de ideologizar la reflexión creyente.

Hoy, después de dieciséis años de su muerte, se puede reconocer que su iniciativa ha sido seguida por otros destacados autores que recogen el 
valioso aporte de su reflexión, lo que de algún modo confirma su intuición. Si bien este aporte filosófico no es del todo original, puesto que se basa en el pensamiento de su maestro Xavier Zubiri (1898 - 1983), se reconoce en su trabajo la capacidad de orientar y vincular tal filosofía, entendida como presupuesto interpretativo, con la Teología de la Liberación, otorgándole así a ésta un estatuto episternológico coherente. En otras palabras: es el esfuerzo por poner en diálogo el pensar filosófico de la realidad con una perspectiva teológica que tiene por objeto encargarse del Dios que se revela y padece en la realidad histórica; de tal modo que esta Filosofía se consrituya en fundamento para un pensar teológico latinoamericano.

El presente artículo tiene por objeto presentar algunos aspectos centrales de la filosofía de Ellacuría que le han permitido establecer nuevas comprensiones de la relación Dios-mundo. En función de ello y para situar al lector, se presenta una breve biografía del autor. Luego se exponen dos elementos de su pensamiento: la comprensión de la inteligencia humana y el objetivo de la Filosofía. De esta última se analiza la realidad histórica y la trascendencia como objeto de la misma. Es necesario dejar en claro que en este texto no se pretenden mostrar las implicancias teológicas que tiene su filosofía, tarea que corresponde a un momento posterior al presente trabajo.

\section{Antecedentes biográficos de Ellacuría ${ }^{2}$}

Ignacio Ellacuría, de origen vasco (España), estudió Teología en Innsbruck, Austria, teniendo entre sus maestros a Karl Rahner (1904 1984). Se doctoró en Filosofía en Madrid con una tesis sobre el pensamiento de Xavier Zubiri ${ }^{3}$, de quien fue discípulo y asiduo colaborador. Hace también los cursos de Doctorado en Teología, pero no presenta tesis, aunque se sabe que sus reflexiones giraban en torno a Dios y la realidad histónica.

En 1967 regresa a América Latina, donde había llegado por primera vez en 1947 como novicio jesuita para realizar sus estudios en Licenciatura en Filosofía. La Conferencia de Medellín (II Conferencia del Episcopado Latinoamericano en 1968) marca su reflexión y producción teológica; orientándola hacia la liberación de los pueblos que sufren la opresión de estructuras sociales injustas.

Desde 1968 hasta su muerte es miembro del equipo rectoral, denominado "Junta de Directores" de la Universidad Centro Americana 
(UCA), San Salvador, de la que fue un considerado motor incluso antes de llegar a ser su Rector. Ya en 1969 logra que la UCA asuma la revista de Estudios Centro Americanos (ECA), en la que publica muchos de sus artículos filosóficos, teológicos y políticos. En 1972 es nombrado Director del Departamento de Filosofía y en 1973 publica su libro Teología política. En 1974 funda el Centro de Reflexión Teológica en la UCA. Y, a partir del año 1979, ejerce como Rector de la UCA. Tras la muerte de Zubiri (1983), Ellacuría es nombrado Director del Seminario Xavier Zubiri en Madrid; en 1984, junto a Jon Sobrino, funda la Revista Latinoamericana de Teología.

Respecto de su acción política en El Salvador se dedica a procurar una salida negociada entre el gobierno y la guerrilla, basada en la reconciliación y con el fin de hacer posible un proceso de democracia real y de convivencia pacífica. A principios de noviembre de 1989 recibe en Barcelona el Premio de la Fundación Comín, otorgado a la UCA. Asimismo, por la divulgación y defensa de la Teología de la Liberación, a través de su prestigio intelectual y su valiente denuncia de la situación del país, como defensor de la liberación del pueblo, se ganó la enemistad de algunos sectores financieros y militares que le amenazaron con insistencia para que callara su voz.

Finalmente, el 16 de noviembre de 1989 fue asesinado por soldados salvadoreños del propio Ejército Nacional, en la residencia de la Universidad, junto con los jesuitas Ignacio Martín Baró, Segundo Montes, Amando López, Juan Ramón Moreno, Joaquín López y López. Fueron también cruelmente asesinadas Elba Julia Ramos, persona al servicio de la Residencia, y la hija de ésta, Celina, de 15 años. En la actualidad, los restos de Ignacio Ellacuría yacen en la capilla de la UCA.

\section{Presupuestos filos 6 ficos}

\subsection{Introducción}

En estos tiempos se ha estudiado en Teología la pregunta por la relación Dios-hombre tomando su punto de arranque de las filosofías de la denominada época moderna. Se destacan dentro de éstas dos corrientes filosóficas: el idealismo y el materialismo. Desde ellas se ha entendido y proyectado la historia de la humanidad como un todo. Estas dos interpretaciones son contrapuestas, se critican y niegan sistemáticamente, a tal punto que es imposible a nivel teórico su conjugación. 
Hoy en día estas corrientes filosóficas manifiestan un evidente fracaso de las esperanzas ilimitadas puestas en el racionalismo, las ciencias y las ideologías dominantes para forjar un individuo y una sociedad nuevos. En este contexto de pensamientos filosóficos totalizantes y desde su situación de fracaso se inserta el pensamiento de Ignacio Ellacuría. Por ello, para una correcta lectura de su pensamiento es necesario explicitar los presupuestos intelectuales con que trabaja.

\subsection{La comprensión de la inteligencia humana según Zubiri, como marco del pensamiento de Ellacuría}

Ellacuría como filósofo dedica la mayor parte de sus esfuerzos intelectuales a investigar y dar a conocer la obra de Xavier Zubiri, como se puede apreciar en la bibliografía de Ellacuría. Desde 1964 hasta su muerte muchos de sus artículos filosóficos tienen esta finalidad. En 1965 presenta su tesis doctoral en Filosofía sobre La principialidad de la esencia en Xavier Zubiri", en la Universidad Complutense de Madrid. Y su mayor obra filosófica, Filosofía de la Realidad Histórica ${ }^{5}$, está íntegramente basada en el diálogo de Zubiri con otros grandes pensadores de la filosofía occidental, como Hegel y Marx, entre otros. Igualmente, Ellacuría se ocupa de la edición de la obra póstuma de su maestro: El hombre y Dios 6 .

Por otra parte, Ellacuría reconoce en la obra de Zubiri los fundamentos metafísicos y conceptuales para asumir y criticar tanto el idealismo como el materialismo, en sus posturas extremas, desde una perspectiva más realista, pero siempre abarcante de la totalidad del mundo. A partir de Zubiri, busca superar la perspectiva naturalista del materialismo, considerando la actividad histórica de la humanidad como objeto y punto de partida de una filosofía con intención liberadora'.

Ellacuría - siguiendo a Zubiri- critica los presupuestos epistemológicos con que se ha filosofado en Occidente, esencialmente desde los pre-socráticos hasta Heidegger. A su juicio en este período se va constituyendo, poco a poco, el principio interpretativo según el cual "inteligir algo es inteligir que es" "Una cosa, se nos dice, es sentir, otra inteligir. Este enfoque del problema de la inteligencia contiene en el fondo una afirmación: inteligir es posterior a sentir, y esta posterioridad es una oposición"9. Por tanto, el pensamiento filosófico occidental se identifica con un reduccionismo idealista ${ }^{10}$, lo cual es, a su vez, una consecuencia de la logificación de la inteligencia y entificación de la realidad"1. La superación de este reduccionismo idealista es buscada por Zubiri a través del análisis 
de lo que es la inteligencia y de lo que es la realidad, partiendo del principio de que la inteligencia es constitutivamente respectiva de la realidad ${ }^{2}$. Al inteligir le llama inteligencia sentiente y significa que inteligir es un modo de sentir y sentir es un modo de inteligir ${ }^{13}$. Es un solo acto de intelección sentiente o sentir intelectivo por el que se aprehende sentientemente lo real. Esto implica que el sentir intelectivo humano da los contenidos en que se hace presente la formalidad de realidad y esto se debe a que lo aprehendido se impone con una fuerza propia, la fuerza de la realidad. De ahí que el acto primario y principal de toda la función intelectiva es formalmente mera actualización de lo real en la inteligencia sentiente ${ }^{14}$, siendo la realidad lo último y más abarcante y de lo que todo lo demás surge.

Ellacuría hace suyos estos presupuestos epistemológicos en su quehacer filosófico, lo que le lleva a reducir las perspectivas filosóficas modernas respecto a la realidad a dos ámbitos. En uno, constata que hay filosofías que tratan de la realidad desde una perspectiva conceptual y lógica, que sólo asumen formalmente la unidad de la realidad, puesto que las distintas esferas o ámbitos de las cosas reales no formarían una unidad real ni estructural ni procesual. En el otro ámbito, Ellacuría reconoce que otras filosofías comprenden la realidad desde una estricta unidad física de todo lo real, pero que conceptualmente deben tratar en forma diferenciada sus partes, porque el todo tiene diferencias intrínsecas y cualitativas. En síntesis, desde la filosofía moderna se ha pensado la unidad de la realidad en categorías idealistas o materialistas, categorías que se dan especialmente en Hegel y Marx y que han dado como resultado una comprensión dualista de la realidad y en consecuencia parcial de ella. Estas comprensiones, piensa Ellacuría, ban conducido junto a otras causas a una construcción de la bistoria que es incongruente con la realidad del mundo y por último ban llevado a los fracasos de la modemidad.

El hecho de que Ellacuría haga filosofía desde el fracaso de la modernidad no le ubica en contra de su proyecto - ni en la postmodernidad-, sino que a partir de los intentos de la modernidad busca la vía que responda a los desafíos del hombre y la humanidad actuales. Y este camino en Ellacuría consiste en pensar la realidad histórica como unidad desde "el mundo de lo real y lo real del mundo, porque el mundo es físicamente uno y a la vez porque la unidad física del mundo le viene dada por su carácter mismo de realidad, su carácter físico de realidad"15. 


\subsection{El objeto último de la filosofía}

\subsubsection{La "realidad histórica"}

Ellacuría tiene como finalidad de su trabajo intelectual fundamentar el objeto de la filosofía, lo que hace que su trabajo se proponga una meta ambiciosa. Al llevarla a cabo no ignora los cuestionamientos que se hacen a la pregunta por el objeto último de la filosofía, tanto desde otras ciencias como la autocrítica que la misma filosofía hace a sí misma. Dice que desde Aristóteles, con su definición de la filosofía como "la ciencia que se busca", ya se indica que ella es el saber que ante todo busca cuál es su objeto $^{16}$. Para definir este objeto entra en diálogo con la tradición filosófica de Occidente, desde los presocráticos hasta Heidegger, reconociendo que todos de un modo u otro buscan hablar de todas las cosas en cuanto ellas coinciden en algo o son abarcadas y totalizadas por algo; y este algo es lo que hace que todas las cosas sean un todo ${ }^{17}$.

En el punto de arranque reconoce que hay que diferenciar el modo de búsqueda del método de acceso al objeto de la filosofía. Sobre el modo o forma en que se ha tratado la cuestión de la unidad totalizante dice que es diverso, puesto que, por una parte, esta unidad totalizante está dada por la unidad conceptual lógica de las cosas más que por las cosas reales mismas, ya que éstas no formarían una unidad ni estructural ni procesual. Por tanto, el objeto de la filosofía es un concepto abarcador completo. Pero, por otra parte, esta unidad totalizante es dada por la unidad física de todo lo real, lo que implica que el objeto de la filosofía es un todo real. Sobre el método de acceso a esta unidad totalizante, Ellacuría se pregunta si se debe comenzar por la unidad totalizante o por la diversidad separante.

Sin embargo, más allá de los modos de búsqueda y de las formas de acceder al objeto y de definir en qué consiste la unidad totalizante, reconoce que los pensadores clásicos consideran que "la filosofía debe tratar de todas las cosas solo en tanto en cuanto todas ellas forman un todo. Este sería su primer y radical objeto formal: sub ratione totius. $\mathrm{La}$ unidad de este saber estaría en la búsqueda del todo de todas las cosas. Lo que no fuera visto sub ratione totius, sub specie totius, ya no sería filosófico o, si se quiere, metafísico"18. En consecuencia, según nuestro autor, hacer filosofía propiamente tal es hacer metafísica, y hacer metafísica es preguntarse por la realidad que da unidad a la totalidad.

En diálogo con Hegel, Marx y Zubiri, Ellacuría fundamenta cuál debe ser el objeto de la filosofía ${ }^{19}$. De su investigación concluye que hay una 
cierta coincidencia en estos autores respecto a la visión original de la unidad real del mundo, y en el intento por estudiar esa unidad diferenciada como lo más real de la realidad. Lo que le sirve de base para proponer su propia respuesta a esta cuestión: la "realidad histórica". Ellacuría entiende por "realidad histórica" la realidad unitaria intramundana en su proceso bacia formas superiores de realidad, tales como se dan en la persona bumana y en la historia. En efecto, "la realidad histórica" es manifestación suprema y totalizante de todo lo que hay en el mundo. Aunque no deba entenderse como la suma o el flujo de los acontecimientos, sino más bien como una totalidad dinámica, estructural y dialéctica en permanente proceso de autosuperación, que engloba dentro de sí todas las formas de la realidad (física, biológica, personal, social, ética, ontológica) y es el lugar donde todas las modalidades de lo que existe adquieren sentido. Al mismo tiempo es el horizonte a través del cual el campo entero de lo real, incluidas las personas y las comunidades humanas, pueden abrirse a la trascendencia ${ }^{20}$.

Lo que propone Ellacuría al indicar la "realidad histórica" como objeto de la filosofía, no es apuntar a un concepto genérico que abarque todas las cosas y que fuera lo último de todas ellas, puesto que de ese modo se corre el riesgo de igualarlas y vaciarlas. Por el contrario, propone una unidad real de todas las cosas reales, que no es meramente una unidad de semejanza, sino una unidad física y dinámica. En efecto, todas las cosas vienen unas de otras $y$, de un modo u otro, están realmente "interpresentes" en su forma de realidad (aunque no en su individualidad). Por lo mismo, Ellacuría propone analizar esta unidad desde su etapa última, etapa que muestra lo que es hasta ahora la realidad. Esta etapa última no es un concepto ni es una idea o ideal, sino algo que está dado al hombre y que, mientras se hace, se sigue dando al hombre.

La distinción que hace Ellacuría de la realidad intramundana incluye cinco características básicas: unidad, dinamismo, ser dialéctica (pero no univocamente), ser procesual y ser ascendente. Respecto a la unidad de la realidad dice que el principio trascendental es la realidad misma de la cosa real, que por ser real es intrinseca y constitutivamente respectiva a cualquier otra cosa real intramundana y material. Esto quiere decir que esa unidad es anterior a la razón y que la realidad no recibe de ésta la unidad que no tendría de suyo. Por tanto, toda relación o funcionalidad de las cosas les viene dada por este carácter de respectividad de la realidad. En otras palabras, es la realidad misma la que es totalidad, totalidad que le viene de los elementos o momentos básicos de ésta. Los momentos básicos de la 
realidad son: la materia misma, la espaciosidad de lo real, la temporalidad material y el fundamento biológico (o la vida). Estos momentos no son anulados por la unidad, sino que son asumidos, como dice Ellacuría, en relación "evolvente" uno al otro".

Respecto del dinamismo, Ellacuría indica que éste compete a la realidad por sí misma, de modo que no hay motivo para preguntarse por el origen del dinamismo como pregunta distinta del origen de la realidad. Al preguntarse por la identidad de la realidad nos preguntamos por el dinamismo; dinamismo que rompe la identidad de la realidad, al impedirle la plena identificación consigo misma. Al mismo tiempo, esta no-identidad actualiza el dinamismo. Ellacuría define formalmente el dinamismo como un dar de sí, lo que implica que la realidad debe mantener una tensión unitaria entre el sí mismo y el dar. De lo que se desprende que al ser las cosas respectivas unas de otras esa respectividad es dinámica. Por tanto, toda relación (o función) de unas cosas reales a otras es necesariamente dinámica. Pero no se da un tipo de dinamismo obligado en toda respectividad, sino que según como sea la realidad será también ese dinamismo ${ }^{22}$.

Respecto del carácter dialéctico de la realidad, Ellacuría explica que no todo dinamismo intramundano es dialéctico de la misma forma, y esto lo atribuye a que la dialéctica tiene sentidos muy variados. Define como específico y formal de la dialéctica la predominancia de la negación, tanto en lo que se refiere al movimiento como en lo que se refiere a la constitución de la unidad dialéctica -y no sólo en la existencia de contrarios como principio de movimiento ${ }^{23}$.

Y finalmente, respecto del carácter procesual y ascendente de la realidad, dice que la realidad misma se muestra como dando de sí formas superiores de realidad, las cuales se apoyan en las inferiores, ya que de ellas provienen; y éstas, a su vez, se hacen presentes en aquéllas como principios positivos y operantes. Este carácter procesual y ascendente muestra que hay distintas formas de realidad que son posteriores unas de otras y son por lo mismo superiores. Esto significa que se da un proceso estricto de realización, entendiendo por tal un proceso en el cual la realidad va dando de sí, de modo que van apareciendo formas de realidad superiores a partir de las inferiores. Por lo que el mundo de las cosas reales no sólo está abierto a nuevas cosas reales, sino a nuevas formas de realidad en cuanto tal ${ }^{24}$. 
Estos momentos básicos de realidad son los que dan paso a la realidad intramundana, constituida como una totalidad dinámica, estructural y dialéctica que se va haciendo, de modo que llega a un incremento cualitativo de realidad. Pero este incremento o "más" de realidad no se da separado de todos los momentos anteriores del proceso real, sino que lo que se da es un "más" dinámico de realidad desde, en y por la realidad inferior, de modo que ésta se hace presente de muchos modos y siempre necesariamente en la realidad superior. De ahí que Ellacuría indique que "a este último estadio de la realidad, en el cual se hacen presentes todos los demás, es al que llamamos realidad histórica: en él, la realidad es más realidad, porque se halla toda la realidad anterior, pero en esa modalidad que venimos llamando histórica. Es la realidad entera, asumida en el reino social de la libertad. Es la realidad mostrando sus más ricas virtualidades y posibilidades, aún en estado dinámico de desarrollo, pero ya alcanzando el nivel cualitativo metafísico desde el cual la realidad va a seguir dando de sí, pero ya desde el mismo subsuelo de la realidad histórica y sin dejar ya de ser intramundanamente realidad histórica"25. La realidad intramundana por ser innovadora por antonomasia ha dado de sí hasta llegar a la historia y desde la historia está abierta a lo que no es necesaria y exclusivamente intramundano: la trascendencia de lo transmundano.

\subsubsection{La trascendencia de la realidad histórica}

El hecho de que Ellacuría establezca como objeto de la filosofía la realidad histórica no significa un materialismo cerrado en sí mismo y autosuficiente ni un idealismo solapado que ve en la realidad un momento del absoluto. Más bien postula que "el mundo es una unidad estrictamente física, que como tal no abarca posibles realidades no mundanas. Dicho de otro modo la unidad física real y constatable del mundo no admite como 'parte' de esa unidad física algo que no puede entrar en ella, una realidad que no sea intrínsecamente respectiva a ese tipo de realidades que forman unitariamente un mundo" ${ }^{26}$.

A esas realidades extramundanas, Ellacuría las llama transmundanas. Una de esas realidades es Dios ${ }^{27}$. Para él Dios y la realidad intramundana no forman estrictamente un todo, puesto que Dios no es una realidad física, y la unidad de la realidad intramundana es el todo físico. Lo anterior no niega que pueda haber relación entre la realidad intramundana y la extramundana. Por el contrario, la realidad intramundana es trascendentalmente abierta; ello por dos motivos: por el dinamismo abierto que la constituye y porque "dentro del mundo de lo real se da una realidad 
constitutivamente abierta, que es precisamente la realidad humana"2s. E apertura dinámica permite una unidad entre ambas realidades, pero unidad es de otra índole completamente distinta ${ }^{29}$. Del mismo mo esta apertura permite que Dios pueda hacerse presente de alguna for en la realidad intramundana, aunque esa presencia también es de o índole de lo que es la presencia de unas cosas intramundanas respecto otras, es decir, no es actualidad.

Ellacuría define la trascendencia como dar de $\mathbf{s}^{\mathbf{1}^{\circ}}$. Esta concepción la trascendencia traspasa transversalmente toda la visión que este pensar tiene de la realidad. Pero su significado no debe ser aplicado en for unívoca a todo; éste tiene importantes variaciones de acuerdo a la realic que está significando: realidad mundana o transmundana. Sin embar estas distinciones en el significado tienen como momento primario dinamismo abierto de la realidad, dinamismo que Ellacuría también def como dar de sí. Por eso señala que la materia es trascendente, al decir c la materia no es algo previo a todo movimiento ni al tiempo, sino que una realidad dinámica y temporal que da de sí haciendo posible que den a partir de ella otras realidades. La causa de esta condición de materia es que ella es estructuralmente dinámica y abierta. Y e dinamismo estructural que la hace trascender le es propio a la mate como realidad. En palabras de Ellacuría, siguiendo a Zubiri: la realidad trascendente de suyo ${ }^{31}$. En conclusión, realidad y trascendencia $s$ respectivas una de la otra y en ningún caso se contraponen como opuest

Como se ha anunciado más arriba, el concepto de trascendencia Ellacuría tiene distintos niveles de significación. Un primer nivel, el n básico, es el que le es propio a toda realidad material o física y consiste ser una realidad dinámica y abierta. Un segundo nivel, propio del humano, consiste en hacerse cargo de sí mismo; en otras palabras, asumi como realidad. Y, desde ahí, abrirse a lo que es distinto de sí, cor persona y como sociedad (este es el ámbito de la historia). Un ter nivel de significación de la trascendencia tiene relación con la capacic del hombre de reconocer la presencia de lo transmundano en y desde mundano. Estos tres niveles de comprensión de la trascendencia $s$ propios de la materialidad de la realidad.

Por otra parte, la trascendencia en su condición más básica o natu consiste en que la realidad, por ser lo que es (ser algo constitutivameı dinámico), da de sí lo que no es originariamente. O sea, la realidad desg. nuevas realidades. Esto significa que la trascendencia no es entend 
como un mero desarrollo de unas posibilidades dadas en una realidad particular, como es el de las especies que dan como fruto nuevas generaciones de la misma especie, sino como aquello que posibilita una realidad física nueva, desde la mismidad de una especie particular. La realidad trasciende de materia inerte a materia biológica y de materia biológica a vida humana por procesos que están dados por este dinamismo estructural de la realidad física. Procesos que están movidos por la necesidad de las posibilidades, tanto como por el azar (el que es, a su vez, otra posibilidad de la realidad). Por tanto, la trascendencia es una característica propia de la realidad; es condición de su dinamismo inmanente.

Como segundo nivel de la trascendencia tenemos aquella que se da en los seres humanos y que consiste en asumirse conscientemente como tales. Lo anterior implica diversos elementos. Primero que el hombre asume como suyo ese dinamismo que le es propio por ser una realidad física, pasando a ser parte activa en su comportamiento y que le lleva a la plena constitución de la sustantividad individual. De ahí que el hombre se considere a sí mismo como su propia realidad. Este poseerse es en el hombre un dinamismo de personalización. Segundo, el hombre va optando por su propia realidad al leer las cosas reales como instancias o posibilidades $y$ al ir creando nuevas posibilidades. Tercero, el hombre tiene la posibilidad de poner en común la propia vida y lo que se hace en la vida, ofreciendo un sistema común y comunicado de posibilidades. "La actualización social de este sistema común de posibilidades lleva a la mundanización, a la constitución del mundo social, del cual los individuos como personas no forman parte, aunque están en él dinámicamente"32. Como cuarto elemento está la historia, cuyo dinamismo, originado por el dinamismo de la realidad material, ahora ha tomado una forma especial: la praxis histórica. Es praxis, puesto que la acción que realiza el hombre es una acción que lo autorrealiza. Esto se debe a que la acción histórica añade a la naturaleza un novum. Este novum consiste en que la intromisión en la realidad histórica de la actividad humana crea capacidades y se apropia de las posibilidades de la realidad histórica. Es histórica, puesto que es praxis social y no individual. En otras palabras, es el hombre entero que se hace cargo de la realidad, asumiendo unitariamente todos los dinamismos que intervienen en su conformación ${ }^{33}$.

Un tercer nivel de significado de trascendencia es el que Ellacuría identifica con lo transmundano, aunque siempre en estrecha relación con 
lo mundano y leído desde lo mundano. Este tercer nivel de posibilic está dado en el ser humano por el hecho de que la historia es dinámic abierta a aquello que no es necesariamente materialidad. Por tanto, cuan Ellacuría se refiere a lo transmundano como trascendencia no lo h: desde lo que está fuera del mundo, sino desde aquellas fuerzas dinamismos no originados por la realidad histórica ni por la praxis histór. pero que intervienen en la historia transformándola. Esto oblig: reconocer que dichos dinamismos se encarnan en la realidad histónic: mismo tiempo que la transforman desde dentro, y que permiten que hombre se apropie de dichas potencialidades creando nuevas posibilida para la realidad histórica. Por tanto, para Ellacuría la pregunta por trascendencia es una pregunta que está posibilitada tanto por la condic de apertura de la historia humana como por la capacidad de apropiació de creación del hombre, quien reconoce que el otro con el que se $\epsilon$ relacionando no pertenece de suyo a la unidad de la realidad inmaner sino que es una realidad transmundana que responde a otra unidad realidad y que su relación con esta realidad inmanente debe buscars partir de una nueva unidad de realidades. Esta nueva unidad de realida es la historia, ya que en ella se dan todos los momentos anteriores d realidad histórica y porque ella es para el hombre el lugar más propio relación con la realidad transmundana.

\section{Conclusión}

En el presente trabajo se ha querido mostrar cuáles son los aspec centrales del pensamiento filosófico de Ignacio Ellacuría: se ha part mostrando la influencia en él de la filosofía de Xavier Zubiri, en espe respecto de la comprensión de la inteligencia humana. Asimismo, se hecho referencia al objeto último de la filosofía, particularmente a temas de la realidad histórica y de la trascendencia de la realidad hisrór Esto porque Ellacuria se hace cargo, en el fondo de su propuesta, de preguntas fundamentales para todo pensador que busca dar respues las inquietudes intelectuales del hombre moderno. Estas cuestione: pueden formular del siguiente modo: icómo conoce el ser humanc ¿qué conoce en última instancia?. A estas cuestiones es a lo que Ellac busca dar respuesta a través de la inteligencia sentiente y de la reali histórica como objeto último de la filosofía.

A su vez, considera que sólo replanteándose el proceso de conocimí como una capacidad de aprehensión de lo real, anterior a $t$ interpretación humana, como aquello que se nos da realmente pued 
hombre comprender que esa realidad es el objeto último del conocimiento filosófico. Realidad que no es materialismo, puesto que por su propia definición ontológica de ser sí mismo y dar de sí implica procesos de trascendencia al interior de lo mundano y de lo mundano a lo extramundano; trascendencia que se manifiesta en la historia como máxima expresión de la realidad. En este contexto, Ellacuría postula que la trascendencia es una posibilidad de la misma materia, pero que a la vez constituye un novum de la realidad propio de la historia, novum en el cual se realiza el encuentro entre lo mundano y lo divino. Este espacio es el que Ellacuría busca explicitar en su trabajo teológico. Dejamos pues como tarea de otro artículo - complementario del que aquí concluyo - presentar los aspectros centrales de la teología de Ignacio Ellacuría.

\section{Biblografía}

Del Magisterio de la Iglesia:

"Instrucción sobre algunos aspectos de la Teología de la Liberación", de la Congregación para la Doctrina de la Fe. Roma, 1984.

"Instrucción sobre libertad cristiana y liberación", de la Congregación para la Doctrina de la Fe. Roma, 1986.

De Ignacio Ellacuría:

La principialidad de la esencia en Xavier Zubiri (Su tesis doctoral), Universidad Complutense, Madrid, 1965.

"Estudio teológico-pastoral de la 'Instrucción' sobre algunos aspectos de la Teología de la Liberación", en: Revista Latinoamericana de Teologia, 2 (1984) 144 -178 .

"Teología de la liberación y marxismo", en: Revista Latinoamericana de Teología, 20 (1990) 109 -135 (Texto base de la conferencia que dictó en la UCA en noviembre de 1985 y publicado sólo en 1990).

"La función liberadora de la filosofía" en: $E C A$ 435-436 (1985), pp. 45-64.

"Aporte de la teología de la liberación a las religiones abrahámicas en la superación del individualismo y del 
positivismo", en: Revista Latinoamericana $10(198$ 3-28.

"La superación del Reduccionismo idealista en Zubir en: Palacios, X. y Jarauta, Francisco (Eds), Razc Ética y Política. Ed. Anthropos, Barcelona, 1989, 2 PP.

Filosofía de la Realidad Histórica, Ed. Trotta, Madr 1991. 478 pp.

Sobre Ellacuría:

Ellacuría, Ignacio - Scannone, Juan Carlos (Compiladorı Para una filosofía desde América Latina, Editor Pontificia Universidad Javeriana, Santa Fe de Bogo 1992, pp. 283 - 285.

Gimbernat, José - Gómez, Carlos (Eds.) La pasión por libertad. Homenaje a Ignacio Ellacuria, Editorial Ver Divino, Estella (Navarra), 1994, pp. 7 - 16.

Mora Galiana, José. “Ignacio Ellacuría. Perfil biográfiı Pensamiento y praxis histórica" [en línea]. http ensayo.rom.uga.edu/filosofos/spain/ellacuri introd.htm; [fecha de consulta: 13 de diciembre 1999].

De Xavier Zubiri:

El hombre y Dios, Alianza Editorial, Madrid, 1984.

Inteligencia Sentiente, Alianza Editorial, Madrid, 1984. 116.

Otros:

Ferrater Mora, José. Diccionario de filosofía, tomo III, Ariel, Barcelo] 2001. 


\section{Notas}

1 El Magisterio del papa Juan Pablo II se pronunció respecto de la Teología de la Liberación en dos instrucciones. La primera de ellas se titula "Instrucción sobre algunos aspectos de la Teología de la Liberación", de la Congregación para la Doctrina de la Fe. Roma, 1984. Y la segunda instrucción se titula "Instrucción sobre libertad cristiana y liberación", de la Congregación para la Doctrina de la Fe. Roma, 1986. Ellacuría dedica especial atención al estudio crítico de las orientaciones que el Magisterio hace de la Teología de la Liberación, pues reconoce en él la autoridad y la verdad con la que se pronuncia. Aunque la fuerza con que piensa y formula sus críticas puede confundir al lector respecto de su adhesión al Magisterio. Al respecto véase "Estudio teológico-pastoral de la 'Instrucción' sobre algunos aspectos de la Teología de la Liberación", en: Revista Latinoamericana de Teología, 2 (1984) 144 178; "Teología de la liberación y marxismo", en: Revista Latinoamericana de Teología, 20 (1990) 109 - 135 (Texto base de la conferencia que dictó en la Universidad Centroamericana en noviembre de 1985 y publicado en 1990) y "Aporte de la Teología de la Liberación a las religiones abrahámicas en la superación del individualismo y del positivismo", en: Revista Latinoamericana 10 (1987) 3-28.

2 Se pueden obtener algunos datos bibliográficos de Ignacio Ellacuría en diversos textos. A modo de ejemplo señalo los siguientes: Para una filosofía desde América Latina, Compiladores Ellacuria, Ignacio - Scannone, Juan Carlos, Editorial Pontificia Universidad Javeriana, Santa Fe de Bogotá, 1992, pp. 283 - 285; La pasión por la libertad. Homenaje a Ignacio Ellacuría, Gimbernat, José - Gómez, Carlos (Eds.), Editorial Verbo Divino, Estella (Navarra), 1994, pp. 7 - 16. Otro lugar en que se encuentran bibliografías más elaboradas de Ignacio Ellacuría es internet. Una dirección es: Mora Galiana, José. “Ignacio Ellacuría. Perfil biográfico. Pensamiento y praxis histórica" [en línea]. http://ensayo.rom.uga.edu/filosofos/spain/ellacuria/ introd.htm; [fecha de consulta: 13 de diciembre de 1999].

3 De 1962 al 1965 realizó los estudios para el doctorado en Madrid, en la Universidad Complutense, bajo la dirección de Xavier Zubiri quien siempre le consideró como el continuador de su obra. Su tesis doctoral en la Universidad Complutense (Madrid 1965) lleva por título: La principialidad de la esencia en Xavier Zubiri.

4 Op. cit.

s Ellacuría, Ignacio. Filosofía de la Realidad Histórica, Ed. Trotta, Madrid, 1991. 478 p. En adelante citaré como FRH.

- Zubiri, Xavier. El bombre y Dios, Alianza Editorial, Madrid, 1984.

- Cf. Ellacuría, Ignacio. "La función liberadora de la filosofía" en: ECA 435-436 (1985), Pp. 45-64. Véase asimismo del autor "El objeto de la filosof(a", en: FRH, Pp. $17-42$.

- Zubiri, Xavier. Inteligencia Sentiente, Alianza Editorial, Madrid, 1984, p 116. En adelante citaré como IS.

- IS, p. 11. Téngase presente el principio escolástico: "Nihil est in intellectu quod prius non luerit in sensu", esto es, nada hay en el entendimiento que no estuviese antes en los sentidos. Esta afirmación es comentada por José Ferrater Mora de la 
siguiente manera: "Esta frase expresa un principio introducido por muchos auto escolásticos, especialmente los de tendencia aristotélica [...] Algunos autores acenti el carácter radicalmente empirista de esta opinión y manifiestan que en Aristót el entendimiento se reduce de un modo o de otro a las impresiones sensib. Otros autores, en cambio, estiman que aunque Aristóteles 'empezaba' con sentidos (o las percepciones sensibles) no derivaba simplemente el conocimiento los sentidos, sino que lo explicaba como resultado de las operaciones entendimiento sobre los contenidos sensibles. El entendimiento abstrae de tw contenidos las formas. Sin el entendimiento no babria, pues, formas y, por tar. universales, pero éstos no ban sido impuestos o sobrepuestos a la realidad sensible, $s$. extraídos ( $y$ abstraídos) de tal realidad" (Las cursivas son mias). Diccionario flosofia, tomo III, Ariel, Barcelona, 2001, p. 2561.

10 Ellacuría explica que Zubiri considera que casi toda la filosofía peca de idealisme no haber encontrado la forma adecuada de enfrentarse con la realidad y de hace cargo de ella. Véase Ellacuría, Ignacio. “La superación del Reduccionismo ideali en Zubin', en: Palacios, X. y Jarauta, Francisco (Eds.), Razón, Ética y Política. Anthropos, Barcelona, 1989, p. 221.

1I Zubiri define lo que entiende por logificación de la inteligencia y entificación d. realidad en IS del siguiente modo: "la inteligencia se fue subsumien progresivamente en ser declaración de lo que la cosa es, es decir, se lue identificar intelección y logos predicativos", (p 86). "Apoyados en Parménides, tanto Pla como Aristóteles fueron subsumiendo la intelección en el logos. Es lo que pági atrás llamé logificación de la intelección. Pero no es sólo esto, es que entonces inteligido mismo consiste en 'ser'. De lo cual resulta que la realidad no es sino modo de ser. Ciertamente el modo fundamental, pero sin embargo, tan sólo mc de ser: es el esse reale. Es decir, lo real es formalmente ente: realidad sería entid Es lo que llamo la entificación de realidad. Logificación de la inteligencia y entificac de lo real convergen así intrínsecamente: el 'es' de la intelección consistiría en 'es' afirmativo, y el 'es' inteligido sería de carácter entitativo. Esta convergencia trazado en buena medida el cauce de la filosolía europea", (pp. 224-225).

Cf. IS, p. 10.

13 aienso que inteligir consiste formalmente en aprehender lo real como real, y a sentir es aprehender lo real en impresión. Aquí real significa que los caracteres . lo aprehendido tiene en la aprehensión misma los tiene 'en propio', 'de suyo', y sólo en función, por ejemplo, de una respuesta vital. No se trata de cosa real e1 acepción de cosa allende la aprehensión, sino de lo aprehendido mismo er aprehensión pero en cuanto está aprehendido como algo que es 'en propio'. Eque llamo formalidad de realidad. Por esto es por lo que el estudio de la intelecc y el estudio de la realidad son congéneres. Ahora bien, esto es decisivo. Porı como los sentidos nos dan en el sentir humano cosas reales, con todas limitaciones, pero cosas reales, resulta que esta aprehensión de las cosas reales cuanto sentidas es una aprehensión sentiente; pero en cuanto es una aprehensión realidades, es aprehensión intelectiva. De ahí que el sentir humano y la intelecc no sean dos actos numéricamente distintos, cada uno completo en su orden, $s$ que constituyen dos momentos de un solo acto de aprehensión sentiente de lo $r$ es la inteligencia sentiente. No se trata de que sea una intelección verı 
primariamente a lo sensible, sino que se trata del inteligir y del sentir en su propia estructura lormal. No se trata de inteligir lo sensible y de sentir lo inteligi ble, sino de que inteligir y sentir constituyen estructuralmente -si se quiere emplear un vocablo y un conceptó impropios en este lugar- una sola facultad, la inteligencia sentiente. El sentir humano y el inteligir no sólo no se oponen sino que constituyen en su intrínseca y formal unidad un solo y único acto de apre hensión. Este acto en cuanto sentiente es impresión; en cuanto intelectivo es aprehensión de la realidad. Por tanto el acto único y unitario de intelección sentiente es impresión de realidad. Inteligir es un modo de sentir, y sentir es en el hombre un modo de inteligir". IS, pp.12-13.

14 "La intelección es formalmente aprehensión directa de lo real, no a través de representaciones o imágenes; es una aprehensión inmediata de lo real, no fundada en inferencias, razonamientos o cosa similar; es una aprehensión unitaria. La unidad de estos tres momentos es lo que constituye que lo aprehendido lo sea en y por sí mismo". IS, p. 257.

is FRH, p. 28.

17 Cf. FRH, p. 17.

18 FRH, p. 18.

19 O como él mismo dice "sobre qué se debe filosofar, sobre el todo filosófico desde el cual deben verse las partes filosóficas y en el cual éstas deben reasumirse so pena de perder la unidad de lo real $y$, en definitiva, la realidad misma de lo real", en: FRH, p. 29. Por otra parte, Ellacuría sintetiza la propuesta por la unidad real del mundo de cada uno de estos pensadores del siguiente modo: en Hegel es el proceso histórico del Absoluto o el Absoluto historizado en busca de su plena autorrealización y autoidentificación; en Marx es la unidad de la realidad material tal como aparece en la historia de la sociedad y del hombre; y en Zubiri es la realidad unicaria intramundana en su proceso hacia formas superiores de realidad tales como se dan en la persona humana y en la historia. Cf. FRH, p. 29.

20 Cf. FRH, p. 38-40.

21 Cf. FRH, p. 31. Véase también, en el mismo libro, el capítulo I: “La materialidad de la historia", pp. 43-140, en el que desarrolla detalladamente cada uno de los momentos básicos que componen la materialidad y la relación y funcionalidad que tienen entre ellos.

22 Cf. FRH, p. 32. Véase también, en el mismo libro, en el capítulo V, el apartado segundo que lleva por título “La estructura dinámica de la historia”, pp. 446-472.

23 Ellacuría distingue lo que es negación de lo que es destrucción. Lo propio de toda realidad es la negación y relega al hombre la capacidad de destruir, sin por ello anular su capacidad de negar, la que le es propia por ser una realidad histórica. Cf. FRH, pp. 34-35.

24

Cf. FRH, pp. $36-38$. 
2s FRH, p. 39.

26 FRH, p. 25.

27 Cf. FRH, pp. 26 y 27.

28 FRH, p. 28.

29 CF. FRH, p. 27.

so Cf. FRH, pp. 468-472.

31 Cf. FRH, p. 469.

32 FRH, p. 470.

3 Cf. FRH, pp. 471-472. 